\title{
Indicadores de maciez em carnes salgadas e dessecadas: uma revisão
}

\section{Tenderness indicators in salted and dried meat: a review}

\author{
Yuri Montenegro Ishihara $^{1 *}$; Marta Suely Madruga²
}

\begin{abstract}
Resumo
Carnes salgadas e dessecadas são conhecidas e apreciadas em todo o mundo. Muitas vezes são caracterizadas por associarem seu consumo a determinados grupos de pessoas ou de determinadas regiões, e devido a isso, podem ser denominadas de tradicionais. Geralmente possuem tecnologia simples, passada de geração em geração e por esse motivo, há muita variação na qualidade desses produtos. No Brasil destacam-se o charque, o jerked beef e a carne-de-sol. O biltong, a cecina de León, o kilishi, o kaddid e a bresaola são exemplos de carnes salgadas e dessecadas. Apesar da importância desses produtos cárneos, inexistem estudos específicos que retratem sua maciez. E, uma vez que tratase de um dos atributos mais reportados pelos consumidores, sua pesquisa pode auxiliar na aceitação dos produtos cárneos incrementando sua demanda. Nesse contexto, a presente revisão explanou as características de produtos cárneos salgados e dessecados tradicionais relacionadas aos seus aspectos de processamento, e sugeriu os indicadores de maciez - força de cisalhamento, índice de fragmentação miofibrilar, comprimento do sarcômero, quantificação do colágeno - para avaliação da maciez de produtos cárneos, uma vez que são de fácil aplicabilidade e compreendem o estudo dos principais responsáveis pela maciez das carnes, as proteínas miofibrilares e o tecido conjuntivo.
\end{abstract}

Palavras-chave: Salga, textura, indicadores

\begin{abstract}
Salted and dried meats are known and appreciated worldly. Their consumption is often associated to certain groups of people or particular regions, and due to this, they can be called traditional. They usually have simple technology, passed on from generation to generation and for this reason, there is much variation in the quality of these products. In Brazil charque, jerked beef and sun-dried meat stand out. Biltong, cecina de León, kilishi, kaddid and bresaola are other examples of salted and dried meats. Despite the importance of these meat products, there are no specific studies on their tenderness. Since tenderness is one of the attributes most reported by consumers, research may help the acceptance of meat products, increasing their demand. In this context, this review presents the characteristics of traditional salted and dried meat products related to processing aspects and suggested tenderness indicators - shear force, myofibrillar fragmentation index, sarcomere length, collagen quantification to assess the softness of meat products, since they are easy to apply and include the study of the main responsible for meat softness, myofibrillar and connective tissue proteins.
\end{abstract}

Key words: Salting, tenderness, indicators

\footnotetext{
${ }^{1}$ Discente de Doutorado do Programa de Pós-Graduação em Ciência e Tecnologia de Alimentos, Universidade Federal da Paraíba, UFPB, João Pessoa, PB. E-mail: yuriufpb@yahoo.com.br

${ }^{2}$ Prof ${ }^{a}$ do Programa de Pós-Graduação em Ciência e Tecnologia de Alimentos, UFPB, João Pessoa, PB. E-mail: msmadruga@uol. com.br

* Autor para correspondência
} 


\section{Introdução}

As carnes salgadas têm origem imemoriável e são conhecidas em todo mundo. Geralmente possuem tecnologia transmitida de geração em geração e por esse motivo apresentam grandes variações de sabor, composição e consequentemente de vida útil. Apesar do avanço da tecnologia no processamento e conservação dos alimentos dos dias atuais, a salga e a dessecação permaneceram na elaboração de produtos cárneos. É bem verdade que a finalidade dessas operações mudou com o passar dos tempos, mas continuam importantes na definição de qualidade dos alimentos processados. Entretanto, muitas vezes a salga e a dessecação são utilizadas no processamento sem grande controle, especialmente tratando-se da elaboração de produtos cárneos denominados tradicionais, que apresentam características específicas que os associam a um determinado grupo de pessoas, cultura ou região.

O Brasil se destaca no cenário mundial de produção de rebanho bovino. Dados do Instituto Brasileiro de Geografia e Estatística, IBGE (2010a) revelam que a produção de bovinos em 2010 foi de 209,54 milhões de cabeças. Essa informação é confirmada pelo Ministério da Agricultura, Pecuária e Abastecimento (BRASIL, 2013) quando ressalta que o Brasil possui o segundo maior rebanho efetivo do mundo. Destacam-se como produtos cárneos tradicionais brasileiros salgados e dessecados a carne-de-sol, o charque e o jerked beef(CARVALHO JUNIOR, 2002). Para expandir as potencialidades da indústria cárnea, especialmente da indústria de produtos salgados com apelo aos tradicionais, surge a necessidade da melhoria na qualidade desses produtos. Para alcançar esse objetivo de incremento da qualidade, a maciez destaca-se como um dos aspectos mais importantes e inclusive mais reportado pelos consumidores, quando são referidos atributos de qualidade em carnes. Entretanto, ainda não é devidamente investigada especificamente nestes alimentos tradicionais.

A maciez dos produtos salgados e dessecados é diretamente influenciada pelo processo tecnológico a que se submete e a pesquisa de maciez poderia sugerir ou mesmo predizer a aceitação desses produtos pelos consumidores, além de uniformizar suas características. Para tal, podem ser utilizados alguns indicadores como a análise instrumental através da força de cisalhamento ou determinações como do índice de fragmentação miofibrilar, da quantificação do colágeno e a visualização do comprimento do sarcômero por microscopia.

Nesse contexto, a presente revisão pretende explanar características de produtos cárneos salgados e dessecados tradicionais relacionadas aos seus aspectos de processamento e sugerir indicadores para avaliação da maciez desses alimentos.

\section{Carnes salgadas e dessecadas}

Antes do advento do frio na conservação de produtos cárneos, a utilização de técnicas para preservação desses produtos combinava vários processos - salga, secagem ao sol, defumação, marinação e fermentação. Essas técnicas, aplicadas isoladas ou conjuntamente, apesar de serem muito antigas, ainda hoje são usadas na indústria cárnea.

No estudo detalhado sobre a evolução de carnes bovinas salgadas e dessecadas, que são processadas em peças inteiras, Carvalho Junior (2002) reportou uma classificação baseada na composição do produto e na maneira de preparo para o consumo: Produtos com baixo teor de sal que podem ser consumidos sem qualquer preparo culinário, tendo como exemplos o biltong, a cecina de León, o kilishi, o kaddid e a bresaola. Produtos que não necessitam de dessalga, mas que requerem preparo culinário para serem consumidos, um exemplo brasileiro é a carne-de-sol. Produtos que necessitam de dessalga e cocção para o consumo, incluem-se nesse grupo a carne de charque e o jerked beef.

Pesquisas com produtos cárneos salgados $\mathrm{e}$ dessecados têm sido publicados, tendo em vista que estes apresentam características próprias, 
específicas da(s) região(ões) onde são produzidos. São muito apreciados a carne-de-sol, o charque e o jerked beef no Brasil, o biltong na África do Sul, a cecina na Espanha e México, o kilishi oriundo da região de Sohel - Oeste da África , o kaddid na África e sul da Ásia e a bresaola na Itália (HIERRO; DE LA HOZA; ORDÓÑEZ, 2004; MOLINERO et al., 2008; PALEARI et al., 2000; PALEARI et al., 2003; LARA et al., 2003; RUBIO et al., 2007; YOUSSEF et al., 2007; ESSID et al., 2007; ZAIER et al., 2011; NKAMA; BADAU, 2000; NAIDOO; LINDSAY, 2010; YOUSSEF et al., 2011).

O Biltong é um produto cárneo desidratado, tradicional da África do Sul, classificado como um alimento pronto para o consumo (ready to eat - RTE). A palavra biltong é derivada do holandês "bil", que refere-se à alcatra e "tong", que refere-se a tiras. É assim denominada porque as tiras de carne que podem ser de diversas origens como bovina, de aves ou mesmo de pescado, são processadas e o produto final tem forma de "stick", muito apreciado em lanches. Possui em média 65\% de proteína, $1,9 \%$ de gordura, $7,6 \%$ de glicose, de 5 a $10 \%$ de sal (em cloreto de sódio), de 10 a 860 ppm de nitrato (NAIDOO, 2010).

Existem diversos métodos para processar o biltong, já que o processamento tradicional foi passado de geração para geração. Entretanto, alguns passos básicos incluem a seleção da carne, os tipos e concentrações das soluções de vinagre, a marinação e a secagem. Atenção maior é dada à etapa de secagem, pois inicialmente era feita ao sol, mas na atualidade requer controle de temperatura e umidade em equipamentos específicos (NAIDOO, 2010). Apresenta uma vida útil prolongada, e estabilidade microbiana em consequencia da presença sais de cura, ácidos orgânicos e baixos valores de $\mathrm{pH}$ e atividade de água inferior a 0,77 (NAIDOO; LINDSAY, 2010). Hoje em dia muitos consumidores preferem o biltong com teor de umidade relativamente alto (superior a $40 \%$ ) e níveis de atividade de água normalmente variando entre 0,85 e 0,93 (NORTJÉ; BUYS; MINNAAR, 2005).
A Cecina de León é um produto cárneo bovino seco e defumado fabricado tradicionalmente na região de León, noroeste da Espanha. É considerado um produto de umidade intermediária e sua preparação é similar ao pernil curado e seco. Possui uma coloração vermelha típica, sabor defumado e um gosto levemente salgado. É vendido no comércio varejista sob a forma fatiada embalada à vácuo ou em cortes (RUBIO et al., 2007). De acordo com Reyes-Cano et al. (1994) a cecina tem grande aceitação também no México, onde é processada por pequenos produtores, o que acarreta diferenças de composição do produto de acordo com a localidade em que é produzida.

A cecina de León apresenta, em base seca, teor de sal entre $8,6 \%$ e $13 \%$, alto teor de proteínas $(60 \%$ a $75,1 \%$ ), teor de gordura variando de $9,9 \%$ a $28,9 \%$ e umidade entre 52,4\% e 57\% (MOLINERO et al., 2008).

Trata de um produto salgado que já possui IGP - Indicação Geográfica de Procedência (RUBIO et al., 2006), e segundo o Conselho Regulador da Indicação Geográfica de Proteção (ESPANHA, 2012), o produto pode ser processado em indústrias localizadas em toda a Província de León. A altitude média da Província é de $1500 \mathrm{~m}$, associada ao clima continental mediterrâneo de invernos duradouros com temperatura média de $2{ }^{\circ} \mathrm{C}$ e de baixa umidade relativa do ar. Essas condições são ideais para a elaboração da cecina, cujo processo de elaboração dura no mínimo sete meses e é constituído por várias fases: Perfilhado: dá-se forma às diferentes peças; Salga com sal grosso marinho em temperatura de 2 ${ }^{\circ} \mathrm{C}$ a $5{ }^{\circ} \mathrm{C}$ com umidade relativa de $85 \%$; Lavagem com água potável morna para eliminar o sal aderido à superfície dos cortes; Maturação por 30 a 45 dias, na qual elimina-se a água da constituição e o sal penetra de maneira homogênea, favorecendo assim o desenvolvimento da microflora característica; Defumação utilizando-se lenha de carvalho, dura de 12 a 16 dias; Secagem ou cura em secadores naturais providos de janelas com abertura regulável que permita controlar a temperatura (aproximadamente 
$11^{\circ} \mathrm{C}$ ) e umidade de 75 a $80 \%$.

Molinero et al. (2008) ressaltaram que durante o processamento da cecina ocorrem muitas modificações nos nutrientes como a proteólise, lipólise e oxidação. Essas mudanças ocorreram principalmente na etapa de maturação e melhoraram os aspectos sensoriais e propriedades como a textura da cecina. Os autores mencionaram ainda um crescimento de $3 \%$ nos últimos anos de produção da cecina na Espanha, e atualmente é exportada para outros países europeus.

De acordo com Musonge e Njolai (1994), o kilishi, produto cárneo tradicional do oeste da África, é preparado com carne bovina, mas também podem ser usadas as carnes ovinas e caprinas. É muito apreciado pela população muçulmana e é exportado para a Arábia Saudita especialmente durante as peregrinações religiosas anuais. $\mathrm{O}$ processo tradicional de produção do kilishi envolve a remoção de tendões e porções de gordura das carnes para serem finamente cortadas e secas ao sol. Em seguida as lâminas são marinadas numa mistura de ingredientes composta por pimenta do reino, cravo, gengibre, cebola, pimenta doce, açúcar, sal e pasta de amendoim desengordurada (NKAMA; BADAU, 2000). Seguindo novamente para a secagem ao sol e posterior cocção em grelha, ficando pronta para consumo.

Apresenta teor de umidade variando de 10 a $20 \%$, o kilishi é normalmente consumido sob a forma de lanche. Segundo Kalilou, Collignan e Zakhia (1998), o processamento do kilishi em pequena escala apresenta rendimento de 30 a 45 $\mathrm{kg}$ do produto para $100 \mathrm{~kg}$ de carne fresca. Em pesquisa realizada por Mgbemere, Akpapunam e Igene (2011) ao processarem o kilishi da forma tradicional, encontraram valores de $11,6 \%$ para umidade, $49,8 \%$ para proteínas, $11,4 \%$ para gordura, $5,2 \%$ para cinzas, $3,1 \%$ para fibras e $18,9 \%$ para carboidratos.

Estudos apontam para a necessidade de padronização do processamento do kilishi, especialmente para as etapas de secagem e embalagem, definidas como críticas e que podem afetar a qualidade do produto final (JONES et al., 2001; FLORAND, 1995; MUSONGE; NJOLAI, 1994). Estudo recente demonstrou o sucesso na elaboração de um mix de temperos e condimentos para padronizar o processamento em escala industrial (MGBEMERE; AKPAPUNAM; IGENE, 2011) demonstrando evolução no interesse científico do kilishi.

Para Bennani et al. (1995), o kaddid é um produto cárneo muito apreciado em países africanos e do sul da Ásia. É preparado através de um processamento tradicional simples. Para processar o kaddid marroquino pode-se utilizar a carne bovina ou ovina e são obedecidas as etapas de corte da carne em longas peças, salga mista e uso de condimentos como coentro, alho, pimenta e corante. As peças ficam em maturação por 8 a 10 horas e a secagem é feita ao sol por 7 a 10 dias.

Chabbouh et al. (2011) ressaltaram que na Tunísia, o kaddid é processado de forma tradicional, no entanto, cuidados no processamento não são devidamente utilizados e proporcionam produtos finais com qualidade duvidosa. Os autores mencionam ainda que a escolha do tipo de salga (seca ou úmida) deve ser feita de acordo com as características finais do kaddid principalmente relacionadas com a capacidade de retenção de água.

O kaddid é caracterizado por apresentar um forte sabor devido à lipólise e provavelmente devido à oxidação de ácidos graxos livres durante seu processamento. A proteólise também pode ajudar no desenvolvimento do sabor eliminando algumas aminas e/ou aminoácidos que podem ter um papel fundamental na qualidade sensorial do produto (BENNANI; FAID; BOUSETA, 2000).

A bresaola surgiu da necessidade de preservar a carne durante todo o ano, diante da inexistência de outros métodos de conservação de alimentos. Segundo Braghieri et al. (2009) a bresaola já existia em Valtellina e Val Chiavenna, cidades da região da 
Lombardia, Itália, entre os anos de 1.450 e 1.500 . Segundo Paleari et al. (2003), esse produto cárneo é obtido usando diferentes cortes magros do traseiro bovino, entretanto, outras carnes já foram utilizadas para sua fabricação como as carnes de cavalo, veado, javali, cabra e de búfalo. Atualmente no processamento industrial, a carne desossada passa por três etapas:

a) A salga úmida (a carne é "tumbleada" numa mistura de cura para $100 \mathrm{~kg}$ de carne fresca composta por 2,5 $\mathrm{kg}$ de cloreto de sódio, $120 \mathrm{~g}$ de dextrose, $20 \mathrm{~g}$ de nitrito de sódio e especiarias) fica em repouso por 5 a 7 dias à temperatura de 3 a $4{ }^{\circ} \mathrm{C}$;

b) As carnes seguem para uma desidratação composta por sucessivas etapas para redução do peso em até $45-50 \%$ do peso inicial. Apresenta vida de prateleira aproximada de 120 dias;

c) Os produtos curados são lavados e secos para serem embalados à vácuo (PALEARI et al., 2003).

A bresaola também é um produto com IGP (EEC 1263/96), possui um mercado caracterizado por consumidores de alto poder aquisitivo e apresenta produção anual italiana de cerca de 8650 toneladas (PALEARI et al., 2000).

\section{Carnes salgadas no Brasil}

Dentre as carnes salgadas e dessecadas apreciadas no Brasil, destacam-se o charque, o jerked beef e a carne-de-sol. Esta última diferencia-se das demais pela particularidade da desidratação ser muito leve, não a caracterizando assim, como um produto de umidade intermediária, ao contrário do charque e do jerked beef (SHIMOKOMAKI, 2006).

O charque, também conhecido como carne seca ou jabá, é típico do Brasil e possui grande aceitação pela população. É um alimento de atividade de água intermediária (entre 0,70 e 0,75), e não requer o uso do frio para sua conservação (SHIMOKOMAKI, 2006).
O Instituto Brasileiro de Geografia e Estatística (IBGE) em sua última Pesquisa de Orçamentos Familiares constatou que o maior consumo de charque em termos regionais se deu na Região Nordeste, com um consumo anual per capita foi de $1,059 \mathrm{~kg}$, e destaque principalmente para os estados de Pernambuco e da Paraíba com 2,904 kg e 1,849 $\mathrm{kg}$ respectivamente (IBGE, 2010b).

Segundo o Ministério da Agricultura, Pecuária e Abastecimento (MAPA) (BRASIL, 1997) o charque não deve conter mais que $45 \%$ de umidade na porção muscular e não mais que $15 \%$ de resíduo mineral fixo, com uma tolerância de $\pm 5 \%$. De uma forma geral, o charque possui de 20 a $40 \%$ de proteína, de 1 a $19 \%$ de matéria graxa e de 9 a $21 \%$ de cloreto de sódio (GOUVÊA; GOUVÊA, 2007), dependendo do corte cárneo empregado, do grau de gordura e de dessecação utilizados no processamento.

Com o objetivo de melhorar tecnologicamente o charque, as indústrias desenvolveram o jerked beef. Neste, o uso de nitrito é permitido e o teor de umidade máximo definido em legislação específica é superior ao do charque.

No processamento desses produtos, inicialmente as carnes são desossadas e manteadas. Em seguida ocorre a salga úmida, quando as peças de carne são imersas e agitadas constantemente por um período de 50 minutos. A etapa seguinte é a salga seca, onde os pedaços de carne são estendidos sobre um piso recoberto com uma camada de sal. Cada camada de manta é intercalada com uma de sal grosso (cerca de $5 \mathrm{~mm}$ ) até uma altura de 1,80 m aproximadamente, sendo mantidas nessa pilha por um tempo de 24 a 48 horas. Durante uma semana aproximadamente, as pilhas são movidas para outra plataforma, onde recebem adição de sal, de maneira que as peças dispostas na parte superior passam a ocupar a posição inferior da nova pilha. Esta operação é denominada tombagem ou tombamento. Este procedimento é repetido de 24 a 48 horas, visando manter todas as mantas em contato com o sal e com a inversão da pilha, se uniformiza a pressão sobre as mesmas. 
Após estas operações, a carne salgada é imersa rapidamente em um tanque com água corrente, para remoção do sal aderido à superfície da peça. A secagem da carne salgada é o próximo passo, em que se promove a retirada final da água, que pode ser feita em cabines de secagem ou expostas ao sol, método mais frequentemente usado na secagem do charque e do jerked beef (SABADINI et al., 2001).

O MAPA (BRASIL, 2000) determinou parâmetros de qualidade para o jerked beef diferenciados aos do charque, tendo em vista suas especificidades tecnológicas. O produto deve ter um valor máximo de atividade de água de 0,78, umidade na porção muscular igual ou inferior a $55 \%$, não mais de $18,3 \%$ de resíduo mineral fixo total e o máximo de $150 \mathrm{ppm}$ de nitrito e nitrato residual no produto final.

A carne-de-sol é um produto salgado que tem como matérias-primas as carnes bovinas e, eventualmente, caprinas e suínas (SHIMOKOMAKI; FRANCO; CARVALHO JUNIOR, 1987) sendo considerada um alimento de grande teor calórico-proteico, muito apreciada pelas suas características sensoriais pela maioria dos consumidores (NÓBREGA; SCHNEIDER, 1983).

Conforme relatado na pesquisa realizada por Carvalho Junior (2002), a carne-de-sol é elaborada, na quase totalidade, em pequenos estabelecimentos que se dedicam especificamente a essas atividades e em praticamente todos os açougues nordestinos. Seu consumo, todavia, não desapareceu com a modernidade, ao contrário, tem ampliado pelo uso da refrigeração em sua conservação.

Algumas vezes, especialmente em regiões do Brasil, excetuando-se a Nordeste, ocorre confusão entre as denominações de carne-de-sol e charque sendo muitas vezes generalizado com o uso do termo "jabá". Entretanto, nem de perto se assemelha ao charque por se tratar de um produto frescal (AMBIEL, 2004). É um produto semi-dessecado e preservado pelo sal, elaborado principalmente com carne bovina, a partir de tecnologia própria, embora empírica, que imprime ao produto final características que o identificam (VIEIRA NETO, 1982).

Para se fabricar a carne-de-sol, submete-se a carne bovina a um leve processo de salga e desidratação, obtendo-se um produto com características muito semelhantes à carne fresca que apresenta vida útil de 72-96 horas em temperatura ambiente. O sal utilizado na sua produção é mais fino do que o usado para produzir o charque, sendo feita a partir de cortes de toda a carcaça bovina, com umidade de 64-70\% e teor de sal 5-6\% (NORMAN; CORTE, 1985). De acordo com Lira (1998), os teores de umidade variam entre 66,33 e $70,10 \%$, o sal entre 4,69 e $8,45 \%$ e a atividade de água entre 0,92 e 0,97.

Vasconcelos (1986) refere-se que para a fabricação de carne-de-sol, há preferência pela carne de animais gordos, que além de um melhor rendimento, dão uma carne de melhor aceitação comercial pela sua corvermelha mais intensa, sendo o coxão-mole (semimembranosus e adductor femoris) o corte mais apreciado. Os cortes individuais são manteados na espessura de 3 a $4 \mathrm{~cm}$ e em seguida recebem incisões parciais a cada $3 \mathrm{~cm}$ para facilitar a penetração do sal no interior do músculo e a perda de umidade para o ambiente. A seguir, é feita a salga seca esfregando-se generosa quantidade de sal nas peças, as quais são empilhadas sobre uma plataforma para permitir o escoamento do líquido expelido ou colocadas em um tanque, permitindo-se ou não o escoamento do exsudado formado. Após certo tempo de salga, alguns processadores efetuam a lavagem das carnes com o exsudado durante a salga, seguindo posteriormente para dessecação.

Dados do IBGE referentes à pesquisa de orçamentos familiares de 2008 a 2009 (IBGE, 2010b) dão indicativos de que o consumo per capita anual de carne-de-sol na Região Nordeste é de 0,890 $\mathrm{kg}$. O estado da Bahia apresenta o maior consumo com $1,871 \mathrm{~kg}$, seguido do estado do Rio Grande do Norte com 1,585 kg e logo atrás a Paraíba com $1,405 \mathrm{~kg}$. Esses dados reforçam a tese de que se 
trata de um produto de grande importância para a região e que carece de maiores investimentos, desde os cuidados técnicos do processamento incluindo melhoramento tecnológico até a comercialização.

Com o objetivo de compilar informações e assim facilitar o entendimento, são apresentadas na Tabela
1 algumas características das principais carnes salgadas consumidas no Brasil, quanto aos aspectos de processamento e composição. Nota-se que diante das similaridades, há a formação de dois grupos. $\mathrm{O}$ primeiro formado pela carne-de-sol, carne soleada e manta de Petrolina e o segundo compondo o charque e o jerked beef.

Tabela 1. Características das principais carnes salgadas brasileiras quanto aos aspectos de processamento e composição.

\begin{tabular}{|c|c|c|c|c|c|}
\hline Parâmetros & Carne-de-sol & Carne soleada & $\begin{array}{l}\text { Manta de } \\
\text { Petrolina }\end{array}$ & Charque & Jerked beef \\
\hline Matéria-prima & $\begin{array}{l}\text { Cortes nobres } \\
\text { bovinos }^{\mathrm{a}}\end{array}$ & $\begin{array}{l}\text { Coxão duro } \\
\text { bovino }^{c}\end{array}$ & Manta ovina $^{\mathrm{d}}$ & Dianteiro bovino ${ }^{\mathrm{a}}$ & $\begin{array}{l}\text { Dianteiro ou } \\
\text { traseiro bovino }\end{array}$ \\
\hline Salga & $10 \%$ por 4 horas $^{\mathrm{b}}$ & $3 \%$ por $5-6$ horas $^{c}$ & $\mathrm{Seca}^{\mathrm{d}}$ & $\begin{array}{l}\text { Úmida, seca e } \\
\text { tombos }^{\mathrm{a}}\end{array}$ & $\begin{array}{l}\text { Úmida, seca e } \\
\text { tombos }^{\mathrm{a}}\end{array}$ \\
\hline Secagem & $\begin{array}{l}\text { Ambiente por } 30 \\
\text { minutos }^{\mathrm{b}}\end{array}$ & $\begin{array}{l}\text { Ambiente por } 18 \\
\text { horas }^{\mathrm{c}}\end{array}$ & $\begin{array}{c}\text { Sol por } 3 \text { a } 5 \\
\text { horas }^{\text {d }}\end{array}$ & Ao sol ${ }^{\mathrm{a}}$ & Ao sol ${ }^{\mathrm{a}}$ \\
\hline Vida útil & $\begin{array}{c}\text { 3-4 dias } \\
\text { (ambiente) }\end{array}$ & $2-3 \operatorname{dias}^{\mathrm{c}}$ & Não informado & 6 meses $^{\mathrm{a}}$ & 6 meses $^{\mathrm{a}}$ \\
\hline Teor de sal & $5-6 \%{ }^{a}$ & $2,7 \%{ }^{\mathrm{c}}$ & $1,93 \%{ }^{\mathrm{d}}$ & $10-20 \%{ }^{\mathrm{a}}$ & $18 \% \%^{\mathrm{a}}$ \\
\hline Umidade & Máximo $64-70 \%$ a & $65-73 \% \%^{c}$ & $67-72 \%$ d & $40-50 \% \%^{a}$ & Máximo 55\%a \\
\hline Atividade de água & $0,92^{\mathrm{a}}$ & $0,97^{\mathrm{c}}$ & $0,97^{\mathrm{d}}$ & $0,70-0,75^{\mathrm{a}}$ & $0,78^{\mathrm{a}}$ \\
\hline $\begin{array}{l}\text { Adição de } \\
\text { aditivos }\end{array}$ & Ausente $^{\mathrm{a}}$ & Ausente $^{c}$ & Ausente $^{\mathrm{d}}$ & Ausente $^{\mathrm{a}}$ & $\begin{array}{l}\text { Nitrito de sódio } \\
\text { Máximo } 150 \\
\text { ppma }^{\mathrm{a}}\end{array}$ \\
\hline Embalagem & Ausente $^{\mathrm{a}}$ & $\begin{array}{l}\text { Presente e com } \\
\text { vácuo }^{\mathrm{c}}\end{array}$ & Ausente $^{\mathrm{d}}$ & $\begin{array}{l}\text { Presente e com/ } \\
\text { sem vácuo }\end{array}$ & $\begin{array}{l}\text { Presente e com } \\
\text { vácuo }^{\mathrm{a}}\end{array}$ \\
\hline Legislação & Ausente & Ausente & Ausente & $\begin{array}{c}\text { RIISPOA } \\
\text { (Decreto n } 30691 \\
\text { de } 29 / 03 / 1952- \\
\text { MAPA) }\end{array}$ & $\begin{array}{c}\text { Instrução } \\
\text { Normativa } n^{\circ} 22 \\
\text { de } 31 / 07 / 2000- \\
\text { MAPA) }\end{array}$ \\
\hline
\end{tabular}

Fonte: aLira e Shimokomaki (1998); ${ }^{\mathrm{b}}$ Salviano (2011); ${ }^{\mathrm{c}}$ Alves et al. (2010); ${ }^{\mathrm{d}}$ Pedrosa (2010).

Ao analisar as carnes do primeiro grupo especificamente a Manta de Petrolina e mediante as informações constantes nos trabalhos de Madruga e Bressan (2011) e Costa et al. (2011), percebe-se que a manta caracteriza-se como uma carne-de-sol elaborada com carne caprina ou ovina denominada dessa forma porque possui potencial para indicação geográfica (IG). Quanto à denominação "carne soleada", há poucos estudos relativos a esse produto e de acordo as informações constantes em Alves et al. (2010) chega-se à conclusão que trata-se de uma simples variação dos parâmetros de salga e secagem do processamento da carnede-sol, fato este muito frequente tendo em vista a inexistência de padrões oficiais de identidade e qualidade. 


\section{Indicadores de maciez em produtos cárneos}

A maciez é um dos atributos mais importantes na aceitação e satisfação do consumidor de carnes, além de ser um fator decisivo para a aquisição desses alimentos, o consumidor consegue discernir entre diferentes categorias de maciez e inclusive está disposto a pagar mais pela aquisição de carnes macias (BOLEMAN et al., 1997).

Pesquisas impulsionadas pelas demandas do consumidor e da indústria cárnea têm sido exaustivamente realizadas na tentativa de alcançar o domínio de técnicas que sejam adequadas à determinação da maciez em produtos cárneos (JATURASITHA et al., 2004; MANÇO, 2006; SANTOS, 2006, ALVES; GOES; MANCIO, 2005). No entanto, tratando-se especificamente de carnes salgadas e dessecadas tradicionais, são poucos os estudos de maciez relativos a esses produtos.

Ramos e Gomide (2007) ressaltaram que devido à complexidade dos músculos e tecidos associados, a maciez é influenciada por uma série de fatores, sendo função do tamanho do feixe de fibras musculares e do tecido conectivo (perimísio) que o envolve. O tamanho dos feixes de fibras musculares não é apenas determinado pelo número de fibras, mas também pelo diâmetro dessas. Assim, duas estruturas na carne são diretamente responsáveis pelo seu grau de maciez: o tecido conjuntivo e as fibras musculares.

Neste contexto, Alves e Mancio (2007) complementaram que a dureza em carnes resulta de dois componentes: a dureza residual causada pelo tecido conjuntivo (colágeno e elastina) e a dureza de actomiosina causada pelas proteínas miofibrilares. Essa divisão poderia explicar resultados conflitantes encontrados na literatura sobre variações de maciez ou dureza da carne e também porque em certos trabalhos foram mostradas correlações entre quantidade de tecido conjuntivo e dureza, enquanto em outros a correlação não foi boa, talvez devido ao fato dos tecidos conjuntivos contribuírem com apenas um dos dois fatores responsáveis pela dureza. Consequentemente, naqueles músculos (ou animais) em que o teor de tecido conjuntivo é alto, este irá contribuir com maior parcela para a dureza e a quantidade de tecido conjuntivo estará positivamente relacionada com a dureza ou negativamente relacionada com a maciez.

Ao estudar a textura do charque relacionada à sua composiçãoquímica, Youssefetal.(2007)verificaram que dentre os diversos fatores influenciadores na textura final do produto, destacam-se a presença de ligações cruzadas de colágeno e, principalmente, a associação desses componentes (multifatores) com as proteínas miofibrilares, os quais provocam eventos bioquímicos dinâmicos como a ligação com as moléculas de água remanescentes à salga e dessecação.

Outro fator também importante no que tange à textura do charque e do jerked beef, refere-se ao fato de que, considerados como produtos resultantes de fermentação (PINTO et al., 2002), esse processo fermentativo pode eventualmente influenciar na qualidade e contribuir na determinação da textura final dos produtos.

Tendo em vista que a maciez pode ser influenciada por diversos fatores, alguns indicadores podem ser utilizados, como a medição da força de cisalhamento (FC), o índice de fragmentação miofibrilar (IFM), o comprimento do sarcômero, e a quantificação do colágeno.

\section{Força de cisalhamento (FC)}

A força máxima (medida em $\mathrm{kgf}$ ou $\mathrm{N}$ ) necessária para cisalhar um pedaço de carne, de dimensões padronizadas, crua ou que foi cozida por procedimentos também padronizados, é tomada como a medida da maciez da carne, utilizandose instrumentos denominados de texturômetros. Salienta-se que uma vez que toda carne, ou pelo menos a maioria, será consumida cozida, a análise de textura e maciez são mais relevantes para a carne cozida em comparação à carne crua (RAMOS; 
GOMIDE, 2007).

Diversos são os estudiosos que relacionaram a maciez de carnes com a força de cisalhamento (FC), medida pelo uso da lâmina Warner Bratzler, e a percepção sensorial dos consumidores. Entretanto, há divergências quanto à classificação e definição de valores limites para a Warner Bratzler Shear Force - WBSF. Alguns desses estudos estão compilados na Tabela 2.

Culler et al. (1978) ao utilizarem uma equipe sensorial treinada, estudaram vários indicadores de maciez em carnes (M. longissimus dorsi) e com relação à WBSF, classificaram em três grupos. Foram ditas duras, quando apresentaram FC de 4,64 $\mathrm{kg} / \mathrm{cm}$, ditas carnes de maciez intermediária quando apresentaram valores de FC de $2,81 \mathrm{~kg} / \mathrm{cm}$ e em carnes macias, quando WBSF foram inferiores a $1,94 \mathrm{~kg} / \mathrm{cm}$. Huffman et al. (1996) ao pesquisarem o comportamento do consumidor no Texas-USA, ao provarem bifes de longissimus dorsi bovino, verificaram que houve uma boa aceitação global para $98 \%$ dos provadores quando o valor da WBSF foi inferior ou igual a $4,1 \mathrm{~kg}$. Shackelford, Wheeler e Koohmaraie (1997) ao estudarem a maciez do M. longissimus dorsi, classificaram em "macia", "intermediária" ou "dura" de acordo com a WBSF para os valores inferiores a $6 \mathrm{~kg}$, entre 6 e $9 \mathrm{~kg}$, ou maior que $9 \mathrm{~kg}$, respectivamente.

Boleman et al. (1997) conseguiram demonstrar que se podem classificar as carnes (longissimus dorsi) de acordo com a FC em três categorias. $\mathrm{Na}$ categoria de carnes muito macias estão as carnes com WBSF de 2,3 a 3,6 kgf, nas moderadamente macias as carnes com WBSF entre 4,1 e 5,4 kgf, e pouco macias, as carnes com WBSF entre 5,9 e 7,2 kgf.
Belew et al. (2003) classificaram 40 músculos da carcaça bovina de acordo com a FC, foram considerados muito macios aqueles que obtiveram valores de FC inferiores a 3,2 kgf; macios, com valores entre 3,2 e 3,9 kgf; intermediários, com valores de FC entre 3,9 kgf e 4,6 kgf; e duros, os músculos que obtiveram valores de $\mathrm{FC}$ acima de 4,6 kgf. Os autores também verificaram que o M. semimembranosus foi classificado como intermediário (FC entre 3,9 e 4,6 kgf).

Destefanis et al. (2008) verificaram que o consumidor (não treinado) classifica como macias as carnes (longissimus thoracis) com FC inferior a 4,37 kgf e como duras as carnes com FC acima de 5,37 kgf. Essa variação da maciez depende de muitos fatores, como tipo de músculo, processo industrial aplicado, preparo da amostra, método de cocção, processo de medição instrumental utilizado.

Sitka (2007) confirmou que a maciez é um parâmetro decisivo para o consumidor de carnes. Entretanto, outros atributos sensoriais como a suculência e o sabor são também muito importantes e foram reportados pelos consumidores em seu estudo. $\mathrm{O}$ autor também ressaltou a problemática gerada através das informações científicas quanto à definição de maciez através da WBSF e da avaliação sensorial, que trata a carne bovina em função de dados específicos para o M. longissimus dorsi. Esse fato é corroborado por Hildrum et al. (2009), ao verificarem diferenças significativas entre os músculos M. infraspinatus, M. tricepsbrachii e M. semimembranosus adductor e demonstrarem que a utilização do M. longissimus dorsi como um indicador de qualidade de todos os músculos é questionável. 
Tabela 2. Classificação de cortes cárneos bovinos quanto à força de cisalhamento com lâmina Warner Braztler.

\begin{tabular}{|c|c|c|c|}
\hline Autores & Músculo & WBSF & Classificação sensorial \\
\hline Culler et al. (1978) & (M. longissimus dorsi) & $\begin{array}{l}4,64 \mathrm{~kg} / \mathrm{cm} \\
2,81 \mathrm{~kg} / \mathrm{cm} \\
1,94 \mathrm{~kg} / \mathrm{cm}\end{array}$ & $\begin{array}{l}\text { dura } \\
\text { maciez intermediária } \\
\text { carne macia }\end{array}$ \\
\hline Huffman et al. (1996) & (M. longissimus dorsi) & $<4,1 \mathrm{kgf}$ & aceitação global 98\% \\
\hline $\begin{array}{l}\text { Shackelford; Wheeler; } \\
\text { Koohmaraie (1997) }\end{array}$ & (M. longissimus dorsi) & $\begin{aligned} & >9 \mathrm{~kg} \\
6 \mathrm{~kg}< & \mathrm{WBSF}<9 \mathrm{~kg} \\
< & <\mathrm{kg}\end{aligned}$ & $\begin{array}{l}\text { dura } \\
\text { intermediária } \\
\text { macia }\end{array}$ \\
\hline Boleman et al. (1997) & (M. longissimus dorsi) & $\begin{array}{l}5,9 \mathrm{kgf}<\mathrm{WBSF}<7,2 \mathrm{kgf} \\
4,1 \mathrm{kgf}<\mathrm{WBSF}<5,4 \mathrm{kgf} \\
2,3 \mathrm{kgf}<\mathrm{WBSF}<3,6 \mathrm{kgf}\end{array}$ & $\begin{array}{l}\text { pouco macia } \\
\text { moderadamente macia } \\
\text { muito macia }\end{array}$ \\
\hline Belew et al. (2003) & $\begin{array}{c}40 \text { músculos (classificação } \\
\text { generalizada) }\end{array}$ & $\begin{aligned} & >4,6 \mathrm{kgf} \\
3,9 \mathrm{kgf} & <\mathrm{WBSF}<4,6 \mathrm{kgf} \\
3,2 \mathrm{kgf} & <\mathrm{WBSF}<3,9 \mathrm{kgf} \\
& <3,2 \mathrm{kgf}\end{aligned}$ & $\begin{array}{l}\text { dura } \\
\text { intermediária }(M . \\
\text { semimembranosus }) \\
\text { macia } \\
\text { muito macia }\end{array}$ \\
\hline Destefanis et al. (2008) & (M. longissimus thoracis) & $\begin{array}{l}>5,37 \mathrm{kgf} \\
<4,37 \mathrm{kgf}\end{array}$ & $\begin{array}{l}\text { dura } \\
\text { macia }\end{array}$ \\
\hline
\end{tabular}

Fonte: Elaboração dos autores.

Diante das informações referenciais relativas à maciez de carnes bovinas e, tratando-se especificamente de WBSF, pode-se concluir que é mais acurado trabalhar com dados, para esse indicador de maciez, específicos ao corte objeto de estudo.

\section{Índice de fragmentação miofibrilar (IFM)}

Segundo Ramos e Gomide (2007), até 1960 as pesquisas relacionadas à maciez de carnes eram restritas ao tecido conjuntivo. Com a melhoria da maciez ocasionada pela maturação, em que nenhuma mudança aparente ocorria no tecido conjuntivo, levou a se ter maior atenção ao componente miofibrilar. A partir dos estudos de Locker, em meados de 1960, que o resfriamento rápido da carcaça acarretava intensa contração muscular e, consequentemente, dureza da carne, estabelecendo-se o início da primeira revolução na ciência da carne. Essas observações conduziram a uma série de trabalhos em que foi mostrado que o diâmetro da fibra muscular está proximamente relacionado à maciez da carne. Posteriormente, com as contribuições de Huxley, para a contração muscular, apresentado em 1969, ficou evidenciado que as proteínas miofibrilares exercem papel importante na estrutura e no metabolismo da fibra muscular, e, por conseguinte, na textura da carne.

A segunda revolução na ciência da carne foi relacionada ao entendimento das causas do amaciamento proporcionado pela maturação, tendose descoberto que a principal mudança que ocorre durante a estocagem post-mortem é a degradação física ou enzimática das proteínas citoesqueléticas (desmina, nebulina e titina), a sua avaliação tem sido realizada especialmente através do Índice de Fragmentação Miofibrilar (IFM). A medida do IFM é baseada no fato de que com a degradação das linhas Z, ocorrida na maturação, as miofibrilas tornam-se "fracas", sendo mais facilmente quebradas em pequenos fragmentos pelo processo de homogeneização. Essa maior facilidade de quebra é relacionada a uma maior maciez.

Ainda referindo-se à maturação, é importante 
mencionar o papel das proteases endógenas e seus inibidores, como o sistema calpaína/calpastatina que modifica a estrutura miofibrilar e é determinante da maciez final da carne maturada (KEMP et al., 2010).

Culler et al. (1978) ao estudarem bifes de longissimus dorsi de 78 carcaças bovinas com graus de maturidade diferentes, verificaram que o IFM foi responsável por mais de 50\% na variação da maciez nas carnes. Comparativamente ao teor de colágeno solúvel e o comprimento de sarcômero, o IFM apresentou-se como o indicador de maciez mais efetivo. Foi estabelecida uma classificação baseada nos valores do IFM na qual foram consideradas "macias" as carnes com IFM de 60 ou acima, como de "maciez intermediária" as carnes com IFM próximo a 50 e como "duras" com IFM abaixo de 50 .

No entanto, Ramos e Gomide (2007) afirmaram que quando amostras de carnes atingem valores altos de IFM (próximos de 100) indicam músculos macios, tendo em vista a grande ruptura da estrutura miofibrilar. Da mesma forma, quando tais valores são baixos (próximos a 30), indicam músculos duros ou menos macios.

Em alguns estudos fica demonstrada a relevância da determinação do IFM para predizer a maciez em carnes. Hawkins et al. (1987) verificaram que o IFM representa uma variação de $19,5 \%$ a $26,4 \%$ a mais na maciez do longissimus dorsi em comparação à força de cisalhamento. Crouse, Koohmaraie e Seideman (1991) verificaram que tanto o IFM quanto a força de cisalhamento são importantes indicadores de maciez, entretanto, variações no IFM não foram observadas quando as carnes foram avaliadas após 6 dias de armazenamento. Isso sugere que a proteólise mensurada através do IFM não pareceu influenciar na maciez de carnes após esse período de armazenamento.

Vestergaard et al. (2000) ao estudarem o IFM nos músculos longissimus dorsi (LD), semitendinosus (ST) e suprasinatus (SU) de bezerros da raça Friesian na Dinamarca, após 24 horas do abate, encontraram valores médios de 31,$8 ; 32,2$ e 22,7, respectivamente. Eles verificaram que houve correlação significativa entre a maciez e o IFM de $0,79(p<0,001)$ para o LD, sugerindo que o IFM é um potencial indicador de maciez especificamente quando se deseja a predição da maciez nas primeiras horas após o abate quando comparado à força de cisalhamento.

\section{Comprimento do sarcômero}

Quando se estudou a relação entre o encolhimento pelo frio e a dureza de carnes, descobriu-se que o comprimento do sarcômero pode ser relacionado com a maciez final de carnes, uma vez que está diretamente relacionado à contração muscular. Estudos nesse sentido não são recentes, tendo já sido estudados desde a década de 70 (PARRISH; VANDELL; CULLER, 1973; CULLER et al., 1978; LOCHNER; KAUFFMAN; MARSH, 1980; JUDGE et al., 1989; OLSSON; HERTZMAN; TORNBERG, 1994).

$\mathrm{Na}$ pesquisa de Smulders et al. (1990) ficou comprovada uma forte relação de dependência entre a maciez do longissimus dorsi mensurada pela WBSF e por uma equipe sensorial com o comprimento do sarcômero. Maiores comprimentos de sarcômeros foram claramente associados com maior maciez. Entretanto, a correlação entre a avaliação sensorial e o comprimento do sarcômero foi de 0,54 sugerindo que o comprimento do sarcômero é responsável por cerca de $30 \%$ da variabilidade observada pela equipe sensorial.

De acordo com Marsh e Leet (1966) o comprimento do sarcômero pode levar tanto ao endurecimento quanto ao amaciamento da carne, dependendo do nível em que ocorre. A dureza da carne, medida pela força de cisalhamento, permanece constante ou aumenta ligeiramente quando o grau de encurtamento do sarcômero encontra-se entre 0 e $20 \%$. Entretanto, a extensão desse encurtamento a níveis maiores acarreta aumento acentuado da dureza, em encurtamentos de 20 a $40 \%$, e em um 
declínio tão acentuado quanto para valores acima de $60 \%$. Essa redução dramática da dureza em condições de contração extrema é explicada pelo fato de que com o aumento do encurtamento, o músculo vai por si mesmo, tornando-se mais macio, por desintegrar sua própria estrutura.

Quando no processamento cárneo ocorre a salga intensa, a exemplo do charque e do jerked beef, promove uma diminuição da área ocupada pelas células musculares assim como um aumento do espaço entre as fibras de colágeno (BISCONTINI et al., 1996) causada pelo aumento da pressão osmótica. Isso reforça a importância do conhecimento das etapas produtivas, uma vez que esses produtos têm a característica de serem originados da tecnologia dos obstáculos associando a salga, a secagem, o uso de aditivos e de embalagens adequadas para a preservação..

Sendo assim, a exemplo da WBSF, torna-se fundamental o conhecimento prévio do comprimento do sarcômero do músculo em estudo no estado de repouso para que se obtenha um parâmetro a ser analisado. Diante dessa necessidade, alguns trabalhos são aqui reportados como o de Heinemann et al. (2002) que, ao pesquisarem o comprimento do sarcômero dos músculos biceps femoris, longissimus dorsi e semimembranosus verificaram diferenças entre eles, encontrando comprimentos médios de $1,88 \mu \mathrm{m}, 1,82 \mu \mathrm{m}$ e $1,95 \mu \mathrm{m}$, respectivamente.

Rhee et al. (2004) pesquisaram em músculos bovinos alguns parâmetros relacionados à maciez, encontraram valores de comprimento de sarcômero para os músculos semimembranosus (SM) e aductor (AD) 1,90 $\mu \mathrm{m}$ e 1,80 $\mu \mathrm{m}$, respectivamente. Kolczak et al. (2003) ao avaliarem as alterações ocorridas nas fibras musculares durante alguns dias em que a carne foi mantida sob refrigeração (4 ${ }^{\circ} \mathrm{C}$ ), constataram que o espaço entre as miofibrilas e o sarcolema, além do espaço entre as miofibrilas sofreu um aumento. O comprimento do sarcômero aumentou devido ao enlargamento das bandas I e essas alterações estruturais ocorreram mais rápidas e intensamente em carnes de animais jovens.

De acordo com Ruddick e Richards (1975) em músculos pré-rigor e em rigor, estendidos contidos ou excisados, observa-se alta correlação ( $\mathrm{r}>$ 0,80 ) entre a maciez e o comprimento médio dos sarcômeros. Esta correlação, no entanto, é menor $(\mathrm{r}=0,68)$ quando os músculos são analisados pósrigor. Mas, mesmo que a medida do comprimento do sarcômero de músculos pós-rigor possa ser considerada uma indicação grosseira do arranjo molecular das miofibrilas, trata-se de um método simples e objetivo para se estimar o grau de contração, sendo útil para se predizer a maciez da carne.

\section{Quantificação do colágeno}

Sabe-se que a maciez das carnes pode ser influenciada pela quantidade de tecido conjuntivo. $\mathrm{O}$ colágeno como principal proteína constituinte desse tecido pode ser quantificado através da determinação da hidroxiprolina, levando-se em consideração que o colágeno possui $12,5 \%$ desse aminoácido e ainda pelo fato de que a hidroxiprolina é exclusiva do colágeno, além de ser de fácil determinação.

Hadlich, Longhini e Mason (2008) mencionaram que quando se estuda a influência do colágeno na maciez de carnes, as características que mais importam são a idade de abate do animal, pois animais mais velhos apresentam menor solubilidade do colágeno devido à estabilidade de suas ligações cruzadas e a localização do músculo estudado, visto que músculos de locomoção apresentam maior quantidade de colágeno que músculos de suporte.

A maciez é dependente da estrutura do tecido conjuntivo e das fibras musculares e da interação destes. A influência do colágeno na textura da carne se dá pelo estado de suas ligações cruzadas, que com o avanço da idade do animal se estabilizam tornando a molécula de colágeno menos solúvel, comprometendo a maciez da carne. Assim, constitui-se um importante fator na verificação de 
diferenças de maciez entre músculos de um mesmo animal (RAMOS; GOMIDE, 2007).

É consenso o fato de que a carne bovina é mais macia à medida que o teor de colágeno é menor. Em alguns estudos foi mostrado que um incremento na solubilidade do colágeno está associado a uma maior maciez (BAILEY; LIGHT, 1989), no entanto, a contribuição do teor de colágeno, assim como sua solubilidade é controversa, uma vez que alguns autores acreditam que não exceda $10 \%$ da maciez total em carnes (BERGE; KUYPERS; KURTH, 1997; DRANSFIELD, 1977).

Ao pesquisar a influência da alimentação e da pastagem na maciez das carnes produzidas de jovens touros, Vestergaard et al. (2000) obtiveram resultados para o colágeno total variando de 0,6 a $0,77 \%$ para o M. semitendinosus e de 0,44 a $0,50 \%$ para o M. longissimus. Oliveira, Soares e Antunes (1998) encontraram valores de colágeno total nos músculos bíceps femoris e triceps braquial de respectivamente 0,62 e 0,81\%. Casey, Crosland e Patterson (1985) ao pesquisarem o teor de colágeno para cortes comerciais de traseiro bovino realizados em oito laboratórios diferentes encontraram uma variação de 0,7 a 1,5\%. Berge et al. (2003) ao estudarem carnes bovinas (longissimus dorsi) advindas de 6 países da Europa encontraram diferenças no teor de colágeno que variou de $1,57 \mathrm{mg}$ a 2,90 mg de Hidroxiprolina/g carne. Em um estudo mais recente e ao pesquisar o teor de colágeno total do músculo longissimus thoracis de bovinos em 15 raças européias, Christensen et al. (2011) encontraram teores variando de 2,02 a 5,33 mg de colágeno/g em base úmida.

\section{Considerações Finais}

A tradição do consumo de carnes salgadas e dessecadas permanece atual, contrariando aqueles que acreditavam que o desenvolvimento da tecnologia iria diminuir ou mesmo extinguir seu consumo. Entretanto, o consumidor não mais aceita alimentos com qualidade duvidosa ou com características variáveis e fazem questão de adquirir tais produtos pois os mesmos caracterizam determinados grupos de pessoas, culturas ou regiões geográficas. Nesse sentido, a busca de conhecimento científico para implementar melhorias tecnológicas é requerida, contudo, alguns produtos não possuem a organização necessária para sua inserção na cadeia produtiva e ficam à margem das condições mínimas requeridas para higiene e aspectos tecnológicos.

Ao se propor indicadores para avaliação de atributos de qualidade pretende-se facilitar o entendimento científico e colaborar no sentido de aplicar tais instrumentos para definição de limites que possam padronizar o processo produtivo de alimentos. Também podem auxiliar na conquista de certificações para assegurar a qualidade do produto. Sendo assim, e considerando os diversos indicadores de maciez em carnes e derivados, são sugeridos a força de cisalhamento, o índice de fragmentação miofibrilar, o comprimento do sarcômero e a quantificação de colágeno, pois, apresentam técnicas simples, eficazes e passíveis de serem aplicadas em tais alimentos. Esses instrumentos avaliativos compõem a pesquisa da dureza no que se referem às contribuições das proteínas miofibrilares e do tecido conjuntivo, responsáveis conjuntamente, pela maciez das carnes.

Importante ressaltar que uma vez divulgado o conhecimento científicoacerca da maciez de produtos cárneos salgados tradicionais, o envolvimento entre os elos da cadeia produtiva deve ser sedimentado. Instâncias governamentais precisam elaborar e divulgar legislações padronizadoras, produtores devem aplicar tais orientações, organismos fiscalizadores devem ser efetivos em sua atribuição, e a sociedade pode colaborar no sentido de fiscalizar e requerer qualidade do produto cárneo adquirido. Isto é, todos os elos devem usufruir de tal conhecimento para que ele possa ser devidamente empregado. 


\section{Referências}

ALVES, D. D.; GOES, R. H. T. B.; MANCIO, A. B. Maciez da carne bovina. Ciência Animal Brasileira, Goiás, v. 6, n. 3, p. 135-149, 2005.

ALVES, D. D.; MANCIO, A. B. Tenderness of bovine meat: a review. Revista da FZVA, Uruguaiana, v. 14, n. 1, p. 193-216, 2007.

ALVES, L. L.; DELBEM, A. C. B.; ABREU, U. G. P.; LARA, J. A. F. Physicochemical and microbiological evaluation of Pantanal's soleada beef. Ciência $e$ Tecnologia de Alimentos, Campinas, v. 30, n. 3, p. 729734, 2010.

AMBIEL, C. Efeitos das concentrações combinadas de cloreto e lactato de sódio na qualidade e conservação de um sucedâneo da carne-de-sol. 2004. Dissertação (Mestrado em Tecnologia de Alimentos) - Universidade Estadual de Campinas, Campinas.

BAILEY, A. J.; LIGHT, N. D. The connective tissue of meat and meat products. London: Elsevier Applied Science, 1989.

BELEW, J. B.; BROOKS, J. C.; McKENNA, D. R.; SAVELL, J. W. Warner-Bratzler shear evaluations of 40 bovine muscles. Meat Science, Texas, v. 64, n. 4, p. $507-$ 512,2003

BENNANI, L.; FAID, M.; BOUSETA, A. Experimental manufacturing of kaddid, a salted dried meat product: Control of microorganisms. European Food Research and Technology, Berlim, v. 211, n. 3, p. 153-157, 2000.

BENNANI, L.; ZENATI, Y.; FAID, M.; ETTAYEBI, M. Physicochemical and microbiological characteristics of a dried salted meat product (Kaddid) in Morocco. Zeitschrift fur Lebensmittel Untersuchung und-Forschung, Berlim, v. 201, n. 6, p. 528-532, 1995.

BERGE, P.; KUYPERS, R.; KURTH, L. B. Collagen crosslink profile and meat texture in two beef muscles. In: INTERNATIONAL CONGRESS OF MEAT SCIENCE AND TECHNOLOGY, 43., 1997, Auckland. Proceedings...Auckland, ago. 1997. p. 548-549.

BERGE, P.; SAÑUDO, C.; SANCHEZ, A.; ALFONSO, A.; STAMATARIS, C.; THORKELSSON, G.; PIASENTIER, E.; FISHER, A. V. Comparison of muscle composition and meat quality traits in diverse commercial lamb types. Journal of Muscle Foods, Connecticut, v. 14, n. 4 , p. $281-300,2003$.

BISCONTINI, T. M. B.; SHIMOKOMAKI, M.; OLIVEIRA, S. F.; ZORN, T. M. T. An ultrastructural observation of charquis, salted and intermediate moisture meat products. Meat Science, Champaign, v. 43, n. 3, p. 351-358, 1996.
BOLEMAN, S. J.; BOLEMANL, S. L.; MILLER, R. K.; TAYLOR, J. F.; CROSS, H. R.; WHEELER, T. L.; KOOHMARAIE, M.; SHACKELFORD, S. D.; MILLER, M. F.; WEST, R. L.; JOHNSON, D. D.; SAVELL, J. W. Consumer evaluation of beef of known categories of tenderness. Journal of Animal Science, Champaigne, v. 75, n. 6, p. 1521-1524, 1997.

BRAGHIERI, A.; GIROLAMI, A.; CARLUCCI, A.; PIAZZOLLA, N.; RIVIEZZI, A. M.; NAPOLITANO, F.Sensory properties affecting acceptability of "bresaola" from podolian young bulls. Journal of Sensory Studies, Manhattan, v. 24, n. 5, p. 677-697, 2009.

BRASIL. Ministério da Agricultura, Pecuária e Abastecimento. 2013. Disponível em: $<$ www.agricultura. gov.br/animal/especies/bovinos-e-bubalinos>. Acesso em: 06 ago 2013.

Ministério da Agricultura, Pecuária e Abastecimento. Departamento de Inspeção e Produtos de Origem Animal. Regulamento de inspeção industrial e sanitária de produtos de origem animal. Aprovado pelo Decreto n 30.691 de 29 de março de 1952, alterado pelo Decreto no 1.225 de 25 de junho de 1962, Decreto $\mathrm{n}^{\circ} 1236$ de 2 de setembro de 1994, Decreto $\mathrm{n}^{\circ} 1.812$ de 8 de fevereiro de 1996, Decreto no 2.244 de 4 de junho de 1997. Brasília, 1997.

Instrução Normativa n. 4, de 31 de março de 2000. Aprova os Regulamentos Técnicos de Identidade e Qualidade do Jerked Beef. Diário Oficial [da] União, Brasília, 2000. Seção 1, p. 6-10.

CARVALHO JUNIOR, B. C. Estudo da evolução das carnes bovinas salgadas no Brasil e desenvolvimento de um produto de conveniência similar à carne-de-sol. 2002. Tese (Doutorado em Tecnologia de Alimentos) Universidade Estadual de Campinas, Campinas.

CASEY, J. C.; CROSLAND, A. R.; PATTERSON, R. L. $\mathrm{S}$. Collagen content of meat carcasses of known history. Meat Science, Great Britain, v. 12, n. 4, p. 189-203, 1985.

CHABBOUH, M.; AHMED, S. B. H.; FARHAT, A.; SAHLI, A.; BELLAGHA, S. Studies on the salting step of tunisian kaddid meat: experimental kinetics, modeling and quality. Food and Bioprocess Technology, Dublin, v. 5, n. 5, p. 1882-1895, 2011.

CHRISTENSEN, M.; ERTBJERG, P.; FAILLA, S.; SAÑUDO, C.; RICHARDSON, R. I.; NUTE, G. R.; OLLETA, J. L.; PANEA, B. ALBERTI, P.; JUÁREZ, M.; HOCQUETTE, J. F.; WILLIAMS, J. L. Relationship between collagen characteristics, lipid content and raw and cooked texture of meat from young bulls of fifteen European breeds. Meat Science, Champaign, v. 87, n. 1, p. 61-65, 2011. 
COSTA, R. G.; MEDEIROS, G. R.; DUARTE, T. F.; PEDROSA, N. A.; VOLTOLINI, T. V.; MADRUGA, M. S. Salted goat and lamb meat: typical regional product of the city of Petrolina, state of Pernambuco. Small Ruminant Research, Little Rock, v. 98, n. 1, p. 51-54, 2011.

CROUSE, J. D.; KOOHMARAIE, M.; SEIDEMAN, S. D. The relationship of muscle fibre size to tenderness of beef. Meat Science, Champaign, v. 30, n. 4, p. 295-302, 1991.

CULlER, R. D.; PARRISH, F. C. JUNIOR; SMITH, G. C.; CROSS, H. R. Relationship of myofibril fragmentation index to certain chemical, physical and sensory characteristics of bovine longissimus muscle. Journal of Food Science, Ames, v. 43, n. 4, p. 1177-1180, 1978.

DESTEFANIS, G.; BRUGIAPAGLIA, A.; BARGE, M. T.; DAL MOLI, E. Relationship between beef consumer tenderness perception and Warner - Bratzler shear force. Meat Science, Champaign, v. 78, n. 3, p. 153-156, 2008.

DRANSFIELD, E. Intramuscular composition and texture of beef muscles. Journal of the Science of Food and Agriculture, Malden, v. 28, n. 9, p. 833-842, 1977.

ESPANHA. Consejo regulador de la indicación geográfica protegida. Cecina de León. 2012.

ESSID, I.; ISMAIL, H. B.; AHMED, S. B. H.; GHEDAMS, R.; HASSOUNA, M. Characterization and technological properties of Staphylococcus xylosus strains isolated from a Tunisian traditional salted meat. Meat Science, Champaign, v. 77, n. 2, p. 204-212, 2007.

FLORAND, P. Transformation des produits agroalimentaires et traitement post-recolte. Rapport de Mission SAT-1 au Niger sur la formulation dun programme de promotion des PME Agro-alimentaires. Rome: FAO, 1995.

GOUVÊA, J. A. G.; GOUVÊA, A. A. L. Tecnologia de fabricação do charque - dossiê técnico. Bahia: Rede de Tecnologia da Bahia, 2007.

HADLICH, J. C.; LONGHINI, L. G. R.; MASON, M. C. A influência do colágeno na textura da carne. Pubvet, Londrina, v. 2, n. 32, Art. 160, 2008.

HAWKINS, R. R.; DAVIS, G. W.; CABLE, J. K.; RAMSEY, C. B. Fragmentation index as an early postmortem predictor of beef tenderness. Journal of Animal Science, Champaign, v. 64, n. 1, p. 171-176, 1987.

HEINEMANN, R. J. B.; PINTO, M. F.; PONSANO, E. H. G.; PERRI, S. H. V. Método simples para estimar encurtamento pelo frio em carne bovina. Ciência Rural,
Santa Maria, v. 32, n. 2, p. 335-339, 2002.

HIERRO, E.; DE LA HOZA, L.; ORDÓÑEZ, J. A. Headspace volatile compounds from salted and occasionally smoked dried meats (cecinas) as affected by animal species. Food Chemistry, Madri, v. 85, n. 4, p. 649-657, 2004.

HILDRUM, K. I.; RODBOTTEN, R.; HOY, M.; BERG, J.; NARUM, B.; WOLD, J. P. Classification of different bovine muscles according to sensory characteristics and Warner Bratzler shear force. Meat Science, Champaign, v. 83, n. 3, p. 302-307, 2009.

HUFFMAN, K. L.; MILLER, M. F.; HOOVER, L. C.; WU, C. K.; BRITTIN, H. C.; RAMSEY, C. B. Effect of beef tenderness on consumer satisfaction with steaks in the home and restaurant. Journal of Animal Science, Champaign, v. 74, n. 1, p. 91-97, 1996.

INSTITUTO BRASILEIRO DE GEOGRAFIA E ESTATÍSTICA - IBGE. Produção da Pecuária Municipal. Rio de Janeiro, 2010a.

Pesquisa de orçamentos familiares 2008-2009.

Rio de Janeiro, 2010b.

JATURASITHA, $\quad$ S.; $\quad$ THIRAWONG, $\quad$ P.; LEANGWUNTA, V.; KREUZER, M. Reducing toughness of beef from Bos indicus draught steers by injection of calcium chloride: effect of concentration and time postmortem. Meat Science, Champaigne, v. 68, n. 1, p. 61-69, 2004.

JONES, M. J.; TANYA, V. M.; MBOFUNG, C. M. F.; FONKEM, D. N.; SILVERSIDE, D. E. Microbiological and Nutritional Evaluation of the West African dried meat product, "kilishi". The Journal of Food Technology in Africa, Nairobi, v. 6, n. 4, p. 126-129, 2001.

JUDGE, M. D.; ABERLE, E. D.; FORREST, J. C.; HEDRICK, H. B.; MERKEL, R. A. Principles of meat science. 2. ed. Dubuque: Kendall/Hunt Publishing Co., 1989.

KALILOU, S.; COLLIGNAN, A.; ZAKHIA, N. Optimizing the traditional processing of beef into kilishi. Meat Science, Champaign, v. 50, n. 1, p. 21-32, 1998.

KEMP, C. M.; SENSKY, P. L.; BARDSLEY, R. G.; BUTTERY, P. J.; PARR, T. Tenderness - an enzymatic view. Meat Science, Champaign, v. 84, n. 2, p. 248-256, 2010.

KOLCZAK, T.; POSPIECH, E.; PALKA, K.; LACKI, J. Changes of myofibrillar and centrifugal drip proteins and shear force of Psoas major and minor and Semitendinosus muscles from calves, heifers and cows during postmortem ageing. Meat Science, Champaign, v. 64, n. 1, p. 69-75, 2003. 
LARA, J. A. F.; SENIGALIA, S. W. B.; OLIVEIRA, T. C. R. M.; DUTRA, I. S.; PINTO, M. F.; SHIMOKOMAKI, M. Evaluation of survival of Staphylococcus aureus and Clostridium botulinum in charqui meats. Meat Science, Champaign, v. 65, n. 1, p. 609-613, 2003.

LIRA, G. M. Avaliação de parâmetros de qualidade da carne-de-sol. 1998. Tese (Doutorado em Ciências Farmacêuticas) - Universidade de São Paulo, São Paulo.

LIRA, G. M.; SHIMOKOMAKI, M., Parâmetros de qualidade da carne-de-sol e dos charques. Higiene Alimentar, São Paulo, v. 12, n. 58, p. 33-35, 1998.

LOCHNER, J. V.; KAUFFMAN, R. G.; MARSH, B. B. Early postmortem cooling rate and beef tenderness. Meat Science, Champaign, v. 4, n. 3, p. 227-241, 1980.

LOCKER, R. H. Degree of muscular contraction as a factor in tenderness of beef. Food Research International, Amsterdam, v. 25, n. 2, p. 304-307, 1960.

MADRUGA, M. S.; BRESSAN, M. C. Goat meats: Description, rational use, certification, processing and technological developments. Small Ruminant Research, Amsterdam, v. 98, n. 1, p. 39-45, 2011.

MANÇO, M. C. Características fisico-químicas, sensoriais e higiênicas da carne bovina em duas classes de maturidade e sob influência da maturação. 2006. Tese (Doutorado em Zootecnia) - Universidade Estadual Paulista, Botucatu.

MARSH, B. B.; LEET, N. G. Studies in meat tenderness. III - The effects cold shortening on tenderness. Journal of Food Science, Chicago, v. 31, n. 4, p. 450-459, 1966.

MGBEMERE, V. N.; AKPAPUNAM, M. A.; IGENE, J. O. Effect of groundnut flour substitution on yield, quality and storage stability of kilishi - a nigerian indigenous dried meat product. African Journal of Food, Agriculture, Nutrition and Development, Nairobi, v. 11, n. 2, p. 47194738, 2011.

MOLINERO, C.; MARTÍNEZ, B.; RUBIO, B.; GONZÁLEZ-FERNÁNDEZ, C.; GARCÍA-CACHÁN, M. D.; JAIME, I. The anatomical origin of raw meat affects the sensory and chemical characteristics of a drycured beef product: cecina de Leon. Food Science and Technology International, Los Angeles, v. 14, n. 3, p. 225-232, 2008.

MUSONGE, P.; NJOLAI, E. N. Drying and infusion during the traditional processing of kilishi. Journal of Food Engineering, London, v. 23, n. 2, p. 159-168, 1994.

NAIDOO, K. The microbial ecology of biltong in South Africa during production and at point-of-sale. 2010. Dissertation (Mestrado em Biologia Celular e Molecular) - University of Witwatersrand, Johannesburg.
NAIDOO, K.; LINDSAY, D. Survival of Listeria monocytogenes, and enterotoxin-producing Staphylococcus aureus and Staphylococcus pasteuri, during two types of biltong-manufacturing processes. Food Control, Amsterdam, v. 21, n. 7, p. 1042-1050, 2010.

NKAMA, I.; BADAU, M. H. Rheological properties of reconstituted kilishi ingredient mix powder. Journal of Food Engineering, Amsterdam, v. 44, n. 1, p. 1-4, 2000.

NÓBREGA, D. M.; SCHNEIDER, T. S. Contribuição ao estudo da carne-de-sol visando melhorar sua conservação. Higiene Alimentar, São Paulo, v. 2, n. 3, p. 150-152, 1983.

NORMAN, G. A.; CORTE, O. O. Dried and salted meats" charque and carne de sol". Rome, Italy: FAO/ UNO. 1985. 32 p. (FAO Production and Health Paper, n. 51).

NORTJÉ, K.; BUYS, E. M.; MINNAAR, A. Effect of $\gamma$-irradiation on the sensory quality of moist beef biltong. Meat Science, Champaign, v. 71, n. 4, p. 603-611, 2005.

OLIVEIRA, L. B.; SOARES, G. J. D.; ANTUNES, P. L. Influência da maturação de carne bovina na solubilidade do colágeno e perdas de peso por cozimento. Revista Brasileira de Agrociência, Pelotas, v. 4, n. 3, p. 166-171, 1998.

OLSSON, U.; HERTZMAN, C.; TORNBERG， E. The influence of low temperature, type of muscle and electrical stimulation on the course of rigor mortis, ageing and tenderness of beef muscles. Meat Science, Champaign, v. 37, n. 1, p. 115-131, 1994.

PALEARI, M. A.; BERETTA, G.; COLOMBO, F.; FOSCHINI, S.; BERTOLO, G.; CAMISASCA, S. Buffalo meat as a salted and cured product. Meat Science, Champaign, v. 54, n. 4, p. 365-367, 2000.

PALEARI, M. A.; MORETTI, V. M.; BERETTA, G.; MANTASTI, T.; BERSANI, C. Cured products from different animal species. Meat Science, Champaign, v. 63, n. 4, p. 485-489, 2003.

PARRISH, F. C.; VANDELL, C. J.; CULLER, R. D. Relationship of tenderness measurements made by the Armour Tenderometer to certain objective, subjective and organoleptic properties of bovine muscle. Journal of Food Science, Chicago, v. 38, n. 7, p. 1214-1219, 1973.

PEDROSA, N. A. Manta de Petrolina - PE: uma alternativa para agregar valor à carne ovina. 2010. Dissertação (Mestrado em Ciência e Tecnologia de Alimentos) - Universidade Federal da Paraíba, João Pessoa.

PINTO, M. F.; PONSANO, E. H. G.; FRANCO, B. D. 
G. M.; SHIMOKOMAKI, S. Charqui meats as fermented meat products: role of bacteria for some sensorial properties development. Meat Science, Champaign, v. 61, n. 2, p. 187-191, 2002.

RAMOS, E. M.; GOMIDE, L. A. M. Avaliação da qualidade de carnes: fundamentos e metodologia. Viçosa: Ed. UFV, 2007.

REYES-CANO, R.; DORANTES-ALVAREZ, L.; HERNANDEZ-SANCHEZ, H.; GUTIERREZ-LOPEZ, G. F. A Traditional intermediate moisture meat: beef cecina. Meat Science, Champaign, v. 36, n. 3, p. 365-370, 1994.

RHEE, M. S.; WHEELER, T. L.; SHACKELFORD, S. D.; KOOHMARAIE, M. Variation in palatability and biochemical traits within and among eleven beef muscles. Journal of Animal Science, Champaign, v. 82, n. 2, p. 534-550, 2004.

RUBIO, B.; MARTÍNEZ, B.; GARCÍA-CACHÁN, M. D.; ROVIRA, J.; JAIME, I. Effect of high pressure preservation on the quality of dry cured beef "Cecina de Leon". Innovative Food Science and Emerging Technologies, Berlin, v.8, n. 1, p. 102-110, 2007.

RUBIO, B.; MARTÍNEZ, B.; GONZÁLEZFERNÁNDEZ， C.; GARCÍA-CACHÁN， M. D.; ROVIRA, J.; JAIME, I. Influence of storage period and packaging method on sliced dry cured beef "Cecina de Leon": Effects on microbiological, physicochemical and sensory quality. Meat Science, Champaign, v. 74, n. 4, p. 710-717, 2006.

RUDDICK, J. E.; RICHARDS, J. F. Comparison of sarcomere length measurement of cooked chicken pectoralis muscle by laser diffraction and oil immersion microcopy. Journal of Food Science, Chicago, v. 40, n. 3, p. 500-501, 1975.

SABADINI, E.; HUBINGER, M. D.; SOBRAL, P. J. A.; CARVALHO JUNIOR, B. C. Alterações da atividade de água e da cor da carne no processo de elaboração da carne salgada desidratada. Ciência e Tecnologia de Alimentos, Campinas, v. 21, n. 1, p. 14-19, 2001.

SAlViAnO, A. T. M. Processamento da carne-desol com carne maturada: qualidade sensorial e textura. 2011. Dissertação (Mestrado em Ciência e Tecnologia de Alimentos) - Universidade Federal da Paraíba, João Pessoa.

SANTOS, G. B. Proteinas miofibrilares e maciez da carne de bovinos superprecoces de diferentes grupos genétios. 2006. Tese (Doutorado em Zootecnia) Universidade Estadual Paulista, Botucatu.

SHACKELFORD, S. D.; WHEELER, T. L.;
KOOHMARAIE, M. Tenderness classification of beef: Evaluation of beef longissimus shear force at 1 or 2 days post mortem as a predictor of aged beef tenderness. Journal of Animal Science, Champaigne v. 75, n. 9, p. 2417-2422, 1997.

SHIMOKOMAKI, M. Charque, jerked beef e carne-desol. In: SHIMOKOMAKI, M.; OLIVO, R.; TERRA, N. N.; FRANC, B. D. G. M. Atualidades em ciência e tecnologia de carnes. São Paulo: Varela, 2006. cap. 4, p. 47-62.

SHIMOKOMAKI, M.; FRANCO, B. D. G. M.; CARVALHO JUNIOR, B. C. C. Charque e produtos afins: tecnologia e conservação - uma revisão. Boletim da Sociedade Brasileira de Ciência e Tecnologia de Alimentos, Campinas, v.2 1, n. 1, p. 25-35, 1987.

SITKA, L. Identification of threshold levels for WarnerBratzler shear force of beef value cuts. 2007. Dissertação (Mestrado em Ciência Animal) - Texas A\&M University, Texas.

SMULDERS, F. J. M.; MARSH, B. B.; SWARTZ, D. R.; RUSSELL, R. L.; HOENECKE, M. E. Beef tenderness and sarcomere length. Meat Science, Champaign, v. 28, n. 4, p. 349-363, 1990.

VASCONCELOS, O. Por cima da carne-seca. Revista Globo Rural, Rio de Janeiro, v. 1, n. 5, p. 15-20, 1986.

VESTERGAARD, M.; THERKILDSEN, M.; HENCKEL, P.; JENSEN, L. R.; ANDERSEN, H. R.; SEJRSEN, K. Influence of feeding intensity, grazing and finishing feeding on meat and eating quality of young bulls and the relationship between muscle fibre characteristics, fibre fragmentation and meat tenderness. Meat Science, Champaign, v. 54, n. 2, p. 187-195, 2000.

VIEIRA NETO, J. Aspectos tecnológicos da fabricação da "carne de sol". 1982. Dissertação (Mestrado em Medicina Veterinária) - Faculdade de Medicina Veterinária, Universidade Federal Fluminense, Niterói.

YOUSSEF, E. Y.; GARCIA, C. E. R.; FIGUEIREDO, B.; SHIMOKOMAKI, M. Níveis residuais de sais de cura e seu efeito antioxidante em jerked beef. Semina: Ciências Agrárias, Londrina, v. 32, n. 2, p. 645-650, 2011.

YOUSSEF, E. Y.; GARCIA, C. E. R.; YAMASHITA, F.; SHIMOKOMAKI, M. Chemical basis for beef charqui meat texture. Brazilian Archives of Biology and Technology, São Paulo, v. 50, n. 4, p. 719-724, 2007.

ZAIER, A.; ESSID, I.; CHABBOUH, M.; BELLAGHA, S.; SAHLI, A. Physico-chemical and microbial caracteristics of traditional and industrial kaddid. In: EUROPEAN DRYING CONFERENCE, 2011, Palma. Anais... Palma: [s.n], 2011. 
